\title{
Enhancing Senior Secondary Students' Performance In Statistical Charts Using Microsoft Excel Spreadsheet Software Package In Rivers State Nigeria
}

\author{
George, Nchelem Rosemary, Kumah, Maxwell Seyram *** \\ * Ph.D, Department Of Mathematics/Statistics, Ignatius Ajuru University Of Education, Rivers State, Nigeria \\ ** Department Of Mathematics \& Ict, St. Teresa’s College Of Education, Hohoe, Ghana \\ DOI: 10.29322/IJSRP.11.12.2021.p12061 \\ http://dx.doi.org/10.29322/IJSRP.11.12.2021.p12061
}

\begin{abstract}
The aim of this study was to investigate how the use of microsoft excel spreadsheet software package can enhance the performance of senior secondary school students in statistical charts in Port Harcourt local government area of Rivers state Nigeria. The study was guided by three research objectives, three research questions and three hypotheses which were tested at 0.05 level of significance. The quasi experimental research design was used. The design presented one experimental group and one control group. A sample of 105 senior secondary class three students were purposively drawn from a population of 3,158 . The instrument used to collect data was named "Achievement Test on Statistical Charts" (ATSC). The instrument was validated and the test retest used to ascertain its internal consistency. A reliability coefficient of 0.77 was established for ATSC. The experimental group was taught statistical chart with Microsoft Excel spreadsheet while the control group was taught with paper and pencil. The two groups were pretested, taught same topics and posttested. Mean, standard deviation and ANCOVA were used for data analysis. The result showed that students taught drawing, reading and adjustment of statistical charts with Microsoft excel spreadsheet outperformed those who were taught with paper and pencil with a statistical significant difference. The male students who were taught with Spreadsheet out performed the female students with no statistical significant difference. It was recommended that excel spreadsheet software package should be incorporated in the teaching of statistical charts because it has the capability to enhance students' performance.
\end{abstract}

Index Terms- Excel, Spreadsheet, Performance, Statistical Charts, Students.

\section{INTRODUCTION}

A 11 over the globe mathematics is regarded as a core and important subject which is utilized in the advancement of scientific, technological and economic development of the society. Thus, the technological development of any nation strongly hinges on the manpower the nation has acquired (Quitzon, 2015). The globe has witnessed the widespread activity relative to new mathematics curricula for all levels of education. In this $21^{\text {st }}$ century almost every activities and attentions are inclined towards technological advancements. This has made mathematics education in this $21^{\text {st }}$ century to be projected into the achievement of mathematics goals and objectives via technological experiences (Maheshwari, 2018).

The use of technological gadgets has found its way in the school sector. The various areas where technology is used in the school include but not limited to purchase of admission forms, processing of school admission, teaching and learning of subject curricula, tracking of academic events, publicity, computation of results, payment of fees et cetera. Charles-Ogan and George (2015) posited that the integration of technologies in the teaching and learning of mathematics indicates the use of technology such as computers and software to teach and learn mathematics contents. Integration of technology is the use of technology to enhance and support the teaching and learning process in education. This suggests why Halat and Perker (2011) buttressed that the integration of technology in the classroom instruction can also be a supportive venture when there is need for students to learn new information or complete assignments. When technology is integrated in the teaching and learning of mathematics, both teachers and students carry out instructional activities with technologies as against the use of paper and pencil.

The integration of technologies in the teaching and learning of mathematics can be carried out with various technological tools such as computers, mathematics software, presentation software, manual calculators, application software, interactive whiteboards, graphing calculators, internet, tablets, social media, overhead projectors, televisions and digital worksheets. The software packages are very vital for the functionality of any computer system in the mathematics classroom. The Computer Algebra System, statistical packages, Dynamic Geometry Packages, spreadsheets, simulators are all the different technologies that can be used to teach and learn mathematics concepts.

Computation and presentation of data using charts in mathematics can be carried out manually with the use of paper and pencil or digitally with the use of technology. The use of technology has increased due to the popularization of modern technological gadgets. The use of technological gadgets requires computers and software packages. George (2019) opined that software packages are classified into general and specific bound. The mathematics softwares are examples of specific bound software because they are subject bound. Not everyone can use the mathematics software. It can only be used by those who specialize 
in the discipline of mathematics. However, there are some software that are not discipline or subject bound. One of such software is the excel spreadsheet.

The excel spreadsheet is defined as a piece of paper or computer programme which is partitioned into rows and columns for the recording, graphing and computation of data. This indicates that a spreadsheet can be manually prepared and used for computation. Dennis (2015) opined that the greatest demerit of the paper spreadsheet is that it cannot be manipulated electronically with icons for fast processing of data. As a result, many people choose to use the computer spreadsheet. Due to the fast acceptance of technology in the classroom, the use of spreadsheets as a learning tool to study abstract concepts in computational areas such as mathematics, physics, chemistry, economics, accounting, and finance has risen in the current period (Oladele, 2019). Spreadsheets have become an indispensable tool for solving mathematical problems and running "what if" dynamic scenarios. Long mathematical problems with many data points may now be solved in less time than is to the usage of spreadsheets. It has also benefited in the reprocessing of archival data without the need for time-consuming procedures. Other advantages of spreadsheets, according to Ndudim (2017), include the ability to perform huge data analysis, formulas, and graphical output without requiring advanced computer programming.

The most popular spreadsheet among users is the Microsoft Excel spreadsheet (Powell, 2020). The unpaid user who use the pirated versions of Microsoft excel programme has increased its users geometrically. The Microsoft excel spreadsheet package comes as a suite which consists of package such as Microsoft word document, Microsoft Office, Microsoft powerpoint, Microsoft outlook and Microsoft Infopath Designer. There are various versions of the Microsoft excel package. The newer versions are updated versions of older version. The versions which end users work with presently are version 2010 and 2016. Excel is a package which is widely used for mathematical computation, statistical modeling and decision making with regards to statistical inference. Hence, excel has become a preferred package for mathematicians and statisticians. The spreadsheet software can help capture, manipulate, run analysis, present data and charts in related specific areas of operation.

Kyriacou (2014) opined that spreadsheet computer programme usually represents information in two dimensional grid of data alongside with formula bars which relate the data. Other activities which the spreadsheet is used for are organization of data into rows and columns, graphing, calculations, sorting and recording of inventories. The data in a computer program spreadsheet can be in any form of numeric values, test, formula, references or functions. The major reasons spreadsheets are used are to: Organize and present data, calculate, payroll, financial accounting and forecast. The use of spreadsheet package to organize and calculate makes it imperative for it to be employed as a mathematical or statistical tool for computation.

There are different types of spreadsheet programmes which are available for use. Gamage and Charles-Ogan (2019) asserted that the choice and usage of any type depends on the user and the features of the spreadsheet with respect to what it performs. Computer Hope (2020) listed Google sheets, iWork Number, Lotus 1-2-3, Lotus Symphony, Libreoffice, OpenOffice, Microsoft Excel and, VisiCalc as examples of spreadsheet programmes which are available for public consumption. Other types of spreadsheet programmes according to Jotform (2020) are Apple Numbers, QUP, Ether Calc, Zoho Sheets, Smartsheet and Apache Open Office.

Drawing and reading of statistical charts such as pie chart, bar chart, histogram and ogive are essential components of mathematics. Statistical charts are used for the pictorial representation of data sets. When data are converted to statistical charts, it makes it easier to be understood and interpreted. Statistical charts helps to summarize data in a vivid way. This may suggest why they are used in organizations and presentation of information to audience. Students therefore need to develop the needed skills to represent data set using statistical charts. A good way to represent data set is the use of computer spreadsheets. The research finding of Topcu (2011) showed that use of spreadsheet software package for mathematics instruction enhanced students' performance in mathematics.

\section{StATEMENT OF THE PROBLEM}

The developmental stage in which the globe is functioning calls for modern and innovative instructional strategies to teach mathematics. To this end, Mynbayeva (2017) asserted that the pedagogy for the $21^{\text {st }}$ century is innovative teaching methods. New teaching approaches are transforming educational environments all across the world, resulting in improved academic achievement among students at all levels. The incorporation of technology into the teaching and learning of school topics is a hallmark of 21stcentury education. It therefore becomes imperative that all stakeholders of education must key into the trend which characterizes this century. Teaching and learning should therefore correspond to the calling of the present era as against the rote learning which is geared towards memorization of taught contents devoid of application. Statistical charts are used in every facet of life. The most frequently used statistical charts are the pie chart and the bar chart. Thus, students need to learn and develop lifelong skills in order to function and succeed in today's and tomorrow's dynamic workplace. This is because every $21^{\text {st }}$ century education must provide students with academic contents, experiences and skills which will foster deeper learning through the purposeful integration of technological gadgets. Most mathematics software are scarce and the available ones in the market are very exorbitant. This creates a scenario where mathematics teachers do not have the required mathematics software to teach mathematics contents. The Microsoft Excel Spreadsheet Package (MESP) is installed in every laptop or computer. Since the MESP can be employed to teach statistical charts, the researchers therefore embarked on this study to investigate whether the use of Microsoft Excel Spreadsheet Package can enhance senior secondary students' performance in the drawing, reading and adjustment of statistical charts.

\section{AIM AND OBJECTIVES OF THE STUDY}

This study was aimed at enhancing the academic performance of senior secondary students in drawing, reading and adjustment of statistical charts (pie and bar charts) using the Microsoft excel spreadsheet package. The objectives were to: 
1. Determine the effect of Microsoft excel spreadsheet package on the academic performance of senior secondary students in the drawing and reading of statistical charts (pie and bar charts).

2. Find out the effect of Microsoft excel spreadsheet package on the academic performance of the male and the female students in the drawing and reading of statistical charts.

3. Ascertain the effect of Microsoft excel spreadsheet package on the academic performance of senior secondary students in adjustment of statistical charts.

\section{Research Questions}

1. What is the difference in the mean performance score of senior secondary students taught drawing and rading of statistical charts (pie and bar chart) using Microsoft Excel Spreadsheet Package (MESP) and those taught using Paper and Pencil (PAP)?

2. What is the difference in the mean performance score of the male and the female students taught drawing and reading of statistical charts (pie and bar charts) using Microsoft Excel Spreadsheet Package (MESP)?

3. How does the mean performance score of senior secondary students taught adjustment of statistical charts using Microsoft Excel Spreadsheet Package (MESP) differ from those taught using Paper and Pencil (PAP)?

\section{Null Hypotheses}

Ho1: There iis ino isignificant idifference iin ithe imean iperformance iscore iof isenior isecondary istudents itaught idrawing and reading of statistical chart using Microsoft Excel Spreadsheet Package (MESP) and those taught using Paper and Pencil (PAP).

Ho2: There iis ino isignificant idifference in ithe imean iperformance iscore iof ithe imale iand ithe ifemale istudents itaught idrawing and reading of statistical charts using Microsoft Excel Spreadsheet Package (MESP).

Ho3: No isignificant idifference iexists in ithe imean iperformance iscore iof $\mathrm{i}$ isenior isecondary istudents itaught iadjustment of statistical charts using Microsoft Excel Spreadsheet Package (MESP) and those taught using Paper and Pencil (PAP).

\section{Research design}

The research design was quasi experimental which presented two (one experimental and one control) intact class groups.

\section{Population of the Study}

The study population comprised of 3,158 students in Senior Secondary Class three (SSC3) in Port Harcourt Local Government Area of Rivers State Nigeria.

\section{Sample and Sampling Technique}

Two schools were sampled for the study. A sample of 105 SSC3 students were drawn from the population using the purposive sampling technique based on the condition of schools that have functional computer laboratory.

\section{Instrument for Data Collection}

Achievement Test on Statistical Charts (ATSC) was the instrument used to collect data. The instrument had ten questions (four on drawing and reading of pie charts, four on drawing and reading of bar charts and two on adjustment of statistical charts. Each question was graded upon ten marks which gave a total of 100 marks. A table blue print was drawn to help distribute the questions evenly into the higher and lower cognitive learning outcome. Also prepared was a marking guide which specified the distribution of marks for specific tasks. Six lesson plans (3 for experimental group and 3 for control group) were prepared for the teaching of thel essons.

\section{Validation of the Instrument}

Validation of the instrument was done by two mathematics educators and one computer studies educator. The face and content review they made were used to restructure the instrument prior to administration.

\section{Reliability of the Instrument}

The instrument, ATSC was subjected to reliability test to ascertain its internal consistency using the test retest method. Twenty five students that did not participate in the main study were used. The reliability coefficient obtained was 0.77 .

\section{Method of Data Collection}

Pretest of ATSC was given to the experimental and the control groups. This was followed by the teaching sessions. Three topics (drawing/reading of pie charts, bar chart and adjustment of statistical charts were taught to each group by the researchers. The teaching session lasted for two weeks. The students in the experimental group were taught using Microsoft Excel Spreadsheet Package while those in the control group were taught using the Paper and Pencil. After the teaching session the two groups were given the posttest of reshuffled ATSC to avoid memorization of test items by the sample students. The two sets of test scripts of the students in the two groups were marked, scored and subjected to statistical analysis.

\section{Method of Data Analysis}

The research questions of the study were analyzed using descriptive statistical tools such as mean and standard deviation, while the null hypotheses were tested inferentially using Analysis of Covariance (ANCOVA).

\section{RESULTS}

Research Question 1: What is the difference in the mean performance score of senior secondary students taught drawing and reading of statistical charts using Microsoft Excel Spreadsheet Package (MESP) and those taught using Paper and Pencil (PAP)? 
Table 1: Mean and standard deviation of performance of students taught drawing and reading of statistical charts using MESP and those taught using PAP

\begin{tabular}{|c|c|c|c|c|c|c|c|}
\hline \multirow[t]{2}{*}{ Group } & & \multirow[t]{2}{*}{$\mathrm{n}$} & \multirow{2}{*}{$\begin{array}{c}\text { Pretest } \\
\mathrm{X} \\
\end{array}$} & \multicolumn{3}{|c|}{ Posttest } & \multirow[t]{2}{*}{ Mean Gain } \\
\hline & & & & SD & X & SD & \\
\hline $\begin{array}{l}\text { Microsoft Excel } \\
\text { Package }\end{array}$ & Spreadsheet & 51 & 25.84 & 5.27 & 63.42 & 12.61 & 37.58 \\
\hline Paper and Pencil & & 54 & $26 . .52$ & 5.19 & 52.04 & 10.82 & 25.52 \\
\hline
\end{tabular}

Table 1 showed the difference in the mean performance score of senior secondary students taught drawing and reading of statistical charts with MESP and those taught with PAP. The result indicated that students taught drawing and reading of statistical charts using MESP performed better (Mean gain $=37.58$ ) than those taught using PAP (Mean gain $=25.52$ ).
Research Question 2: What is the difference in the mean performance score of the male and the female students taught drawing and readimg of statistical charts (pie and bar charts) using Microsoft Excel Spreadsheet Package (MESP)?

Table 2: Mean and standard deviation of mean performance of the male and the female students taught drawing and reading of statistical charts using MESP

\begin{tabular}{lllccccc}
\hline Group & & $\mathrm{n}$ & Pretest & \multicolumn{3}{c}{ Posttest } & \multicolumn{2}{c}{ Mean Gain } \\
MESP & & & $\mathrm{X}$ & $\mathrm{SD}$ & $\mathrm{X}$ & $\mathrm{SD}$ & \\
\hline \multirow{2}{*}{ Male } & 19 & 24.01 & 4.38 & 62.68 & 11.42 & 38.67 \\
& & & & & & & \\
& Female & 32 & 27.67 & 4.22 & 64.16 & 14.70 & 36.49 \\
\hline
\end{tabular}

Table 2 showed the difference in the mean performance score of the male and the students taught drawing and reading of statistical charts with MESP in the experimental group. The result revealed that the male students taught statistical charts using MESP performed better $($ Mean gain $=38.67)$ than their female counterpart $($ Mean gain $=36.47)$ in the same group.
Research Question 3: How does the mean performance score of senior secondary students taught adjustment of statistical charts using Microsoft Excel Spreadsheet Package (MESP) differ from those taught using Paper and Pencil (PAP)?

Table 3: Mean and standard deviation of mean performance score of students taught adjustment of statistical charts using MESP and those taught using PAP

\begin{tabular}{lccccccc}
\hline Group & & $\mathrm{N}$ & Pretest & \multicolumn{2}{c}{ Posttest } & Mean Gain \\
& & & $\mathrm{X}$ & $\mathrm{SD}$ & $\mathrm{X}$ & $\mathrm{SD}$ & \\
\hline $\begin{array}{l}\text { Microsoft } \\
\begin{array}{l}\text { Package } \\
\text { Paper and Pencil }\end{array}\end{array}$ & Spreadsheet & 51 & 14.39 & 4.83 & 60.61 & 13.84 & 46.22 \\
\hline
\end{tabular}

Table 3 showed the difference in the mean performance score of senior secondary students taught adjustment of statistical charts with MESP and those taught with PAP. The result indicated that students taught adjustment of statistical charts using MESP performed better (Mean gain $=46.22$ ) than those taught using PAP $($ Mean gain $=31.03)$.
Ho1: There iis ino isignificant idifference in ithe imean iperformance iscore of senior secondary students taught drawing and reading of statistical chart using Microsoft Excel Spreadsheet Package (MESP) and those taught using Paper and Pencil (PAP).

Table 4: Summary iof iANCOVA ion ithe idifference ibetween ithe iperformance $\mathrm{i} i \mathrm{i}$ iof students taught drawing and reading of statistical chart using MESP and those taught using PAP.

\begin{tabular}{llllll}
\multicolumn{2}{l}{ Dependent Variable: Posttest } & & & \\
\hline iSource & $\begin{array}{c}\text { iType iIII iSum iof } \\
\text { iSquares }\end{array}$ & iDf & iMean iSquare & iF & iSig. \\
\hline Corrected Model & $1536.40 \mathrm{a}$ & 2 & 768.20 & 13.00 & 0.00 \\
Intercept & 8861.67 & 1 & 8861.67 & 149.97 & 0.00
\end{tabular}




\begin{tabular}{llllll} 
Group & 1169.80 & 1 & 1169.80 & 19.80 & 0.00 \\
Pretest & 345.22 & 1 & 345.22 & 5.84 & 0.02 \\
Error & 5436.08 & 102 & 59.09 & & \\
Total & 243773.00 & 105 & & & \\
Corrected Total & 6972.48 & 104 & & & \\
\hline
\end{tabular}

a. $\quad$ R Squared $=.220$ (Adjusted R Squared $=.203$ )

Table 4 showed ithat ithere iwas i isignificant idifference ibetween the performance of students taught drawing and reading of statistical chart with MESP and those taught using paper and pencil $(\mathrm{F} 1=1169.80$, df $=102, \mathrm{p}=0.00<0.05)$. Thus, $\mathrm{H}_{\mathrm{O} 1}$ was rejected at 0.05 significant level.
Ho2: There iis ino isignificant idifference in ithe imean iperformance iscore iof ithe imale iand ithe ifemale istudents itaught idrawing and reading of statistical charts using Microsoft Excel Spreadsheet Package (MESP).

Table 5: Summary iof iANCOVA ion ithe idifference ibetween ithe iperformance iof ithe imale iand ithe ifemale istudents itaught idrawing and reading of statistical charts using MESP.

Dependent Variable: Posttest

\begin{tabular}{llllll}
\hline iSource & iType iIII iSum iof iSquares & iDf & $\begin{array}{l}\text { iMean } \\
\text { iSquare }\end{array}$ & iF & iSig. \\
\hline iCorrected iModel & $606.135 \mathrm{a}$ & 2 & 303.07 & 2.33 & 0.11 \\
iIntercept & 3125.60 & 1 & 3125.60 & 23.97 & 0.00 \\
iGender & 417.66 & 1 & 417.66 & 3.20 & 0.08 \\
iPretest & 260.07 & 1 & 260.07 & 2.00 & 0.17 \\
iError & 4563.23 & 47 & 130.38 & & \\
iTotal & 117060.00 & 51 & & & \\
iCorrected iTotal & 5169.37 & 50 & & & \\
\hline
\end{tabular}

\section{a. $\quad$ R Squared =.117 (Adjusted R Squared $=.067$ )}

Table 5 showed ithat ithere iwas ino isignificant idifference ibetween ithe iperformance iof ithe imale iand ithe ifemale istudents itaught idrawing and reading of statistical chart with $\operatorname{MESP}(\mathrm{F} 1=417.66$, df $=47, \mathrm{p}=0.08>0.05)$. Thus, $\mathrm{H}_{\mathrm{O} 2}$ was retained at 0.05 significant level.
Ho3: No isignificant idifference iexist iin ithe imean iperformance iscore iof $\mathrm{i}$ isenior isecondary istudents itaught iadjustment of statistical charts using Microsoft Excel Spreadsheet Package (MESP) and those taught using Paper and Pencil (PAP).

Table 6: Summary of ANCOVA on the difference between the performance of students taught adjustment of statistical charts using MESP and PAP

\begin{tabular}{|c|c|c|c|c|c|}
\hline iSource & iType iIII iSum iof iSquares & iDf & $\begin{array}{c}\text { iMean } \\
\text { iSquare }\end{array}$ & iF & iSig. \\
\hline Corrected Model & $9376.89 a$ & 2 & 4688.44 & 18.08 & 0.00 \\
\hline Intercept & 2419.34 & 1 & 2419.34 & 9.33 & 0.00 \\
\hline Group & 6122.27 & 1 & 6122.27 & 23.60 & 0.02 \\
\hline Posttest & 384.44 & 1 & 384.44 & 1.48 & 0.23 \\
\hline Error & 23862.54 & 102 & 259.38 & & \\
\hline Total & 219189.00 & 105 & & & \\
\hline Corrected Total & 33239.43 & 104 & & & \\
\hline
\end{tabular}

a. R Squared =.282 (Adjusted R Squared $=.266$ )

Table 6 showed ithat ithere iwas isignificant idifference ibetween ithe iperformance iof istudents itaught iadjustment of statistical chart with MESP and those taught using paper and pencil $(\mathrm{F} 1=$ $384.44, \mathrm{df}=102, \mathrm{p}=0.02<0.05)$. Thus, $\mathrm{H}_{\mathrm{O} 3}$ was rejected at 0.05 significant level.

\section{DISCUSSION OF FINDINGS}

The finding showed that the students who were taught drawing and reading of statistical charts using excel spreadsheet performed better than the students who were taught using paper and pencil. This finding has proved that integration of computer spreadsheet enhanced the students' performance in the taught content. The results also demonstrated a substantial difference in performance between students who were taught to create statistical charts using an excel spreadsheet and those who were taught with paper and pencil. This is consistent with that of Benning and Agyei (2016) and Topcu (2011), who found that students taught mathematics using the spreadsheet teaching technique performed better than those taught using the conventional method. This study, however, contradicts Isiksal and Askar (2005), who found 
that pupils who were taught mathematics using the traditional technique had a higher mean score than those who were taught using an excel spreadsheet.

Male students who were taught statistical charts with MESP did better than their female counterparts in the same group, in this study. This study is consistent with that of Isiksal and Askar (2005), who found that male students who were taught mathematics with autograph outperformed their female counterparts. There was no significant difference in performance between male and female students who were taught using a computer spreadsheet programme.

Students who were taught to adjust statistical charts using excel spreadsheet did better than students who were taught using paper and pencil, according to the findings. The results also demonstrated a substantial difference in performance between students who were taught to alter statistical charts using excel spreadsheet vs those who were taught with paper and pencil. This finding is in agreement with the findings of Akol (2017) which showed that students who were taught geometrical construction using technological gadgets had a higher performance in adjusting and correcting observed errors than those who adjusted and corrected using paper and pencil.

\section{CONCLUSION}

This study concluded that the use of Microsoft Excel Spreadsheet Pakage enhanced the performance of students in the drawing, reading and adjustment of statistical charts better than the use of paper and pencil.

\section{RECOMMENDATIONS}

Based on the findings it was recommended that computer spreadheet packages should be used to teach students statistical charts and other mathematics concepts that are compatible with spreadsheet.

\section{REFERENCES}

[1] Akol, M.M. (2017). Spreadsheet interactive software package and students; perfoemance in mathematics. Journal of Systematic Research and Trends, $1(2), 34-45$.

[2] Benning, I. \& Agyei, D.D. (2016). Effect of using spreadsheet in teaching quadratic functions on the performance of senior high school students. International Journal of Education, Learning and Development, 4(1), 11-29. https://www.eajournals.org
[3] Charles-Ogan, G.I. \& George, N.R. (2015). Information communication technology and mathematics curricumlum reform. In Olele \& Cheta (Eds). Technology-drivrn curriculum for 21st century learners, 29-39.

[4] Computer Hope (2020). What is spreadsheet? https://www.computerhope.com>sp

[5] Dennis, F. (2015). Merits and demerits of paper and computer spreadsheets. Hillon Press.

[6] Gamage, T. \& Charles-ogan, G.I. (2019). GeoGebra software and students; performance in teaching and learning of circle geometry. Journal of Mathematical Association of Nigeria, 44(1), 480-490.

[7] George, N.R. (2019). Integrating technology in the teaching and learning of mathematics. An undergraduate lecture monograph in mathematics method course.

[8] Halat, E. \& Perker M. (2011). The impact of mathematical representations developed through webquest and spreadsheet activities on the motivation of pre-service elementary teachers. The Turkish online Journal of Educational Technology. 10(2), 259-267.

[9] Isiksal, M. \& Askar, P. (2005). The effect of spreadsheet and geometry software on the achievement and self-efficacy of 7 th grade students. Doi: $10.1080 / 00131880500287815$

[10] Jotform (2020). 12 best spreadsheets software options to try in 2021 https://www.jotform.com

[11] Kyriacou, C. (2014). Features of Microsoft excel you should be using. https://learn.filtered.com

[12] Maheshwari, V.k. (2018). Mathematics laboratory and lab method activity oriented pedagogy in mathematics teaching. http://www.vkmaheshwari.com

[13] Mynbayeva, A. (2017). Pedagogy of the twenty-first century: Innovative teaching methods. https://www.intechopen.com>chapt

[14] Ndudim, C. (2017). 21st century mathematics teacher and classroom. Banner Publications.

[15] OLadele, V. J. (2019). The classroom instruction and technology. Rowell Printing Press.

[16] Powell, E. (2020). Why is excel the most popular spreadsheet? Quora.com?

[17] Quitzon, K. (2015). The importance of technology for development https://borgenprojet.org>importance

[18] Topcu, A. (2011). Effect of using speadheets on secondary school students' self-efficacy for algebra. International Journal of Mathematical Education in Scienec Technology

\section{AUTHORS}

First Author - George, Nchelem Rosemary, Ph.D

Department Of Mathematics/Statistics, Ignatius Ajuru University

Of Education, Rivers State, Nigeria

Second Author - Kumah, Maxwell Seyram, Department Of

Mathematics \& ICT, St. Teresa's College Of Education

Hohoe, Ghana 